\title{
Supporting Information \\ High-Efficiency Nonfullerene Polymer Solar Cells Enabling by Integration of Film-Morphology Optimization, Donor Selection, and Interfacial Engineering
}

\author{
Xin Zhang, Weiping Li, Jiannian Yao and Chuanlang Zhan* \\ Beijing National Laboratory for Molecular Sciences, CAS Key Laboratory of Photochemistry, \\ Institute of Chemistry, Chinese Academy of Sciences, Beijing 100080, P. R. China. Tel/Fax: \\ +86-10-82616517/82617312, E-mail: (C.Z.) clzhan@iccas.ac.cn.
}




\section{Contents}

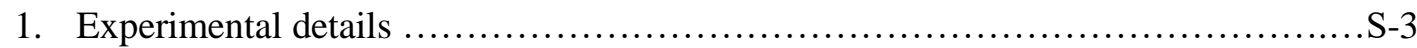

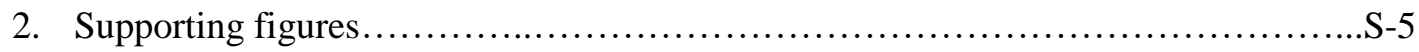

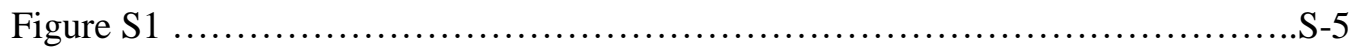

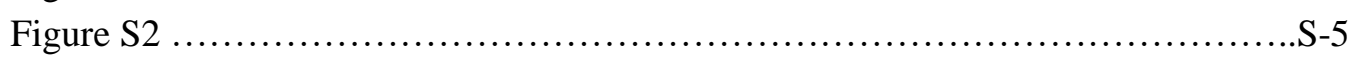

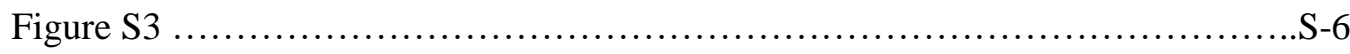

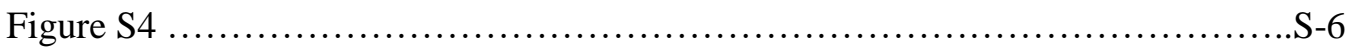

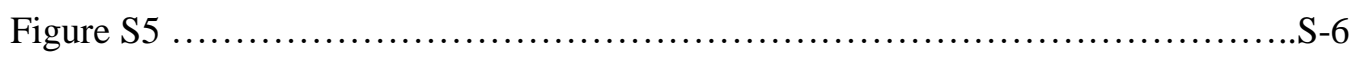

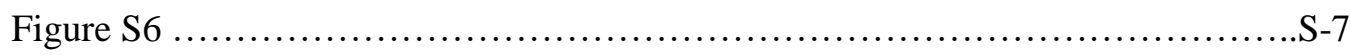

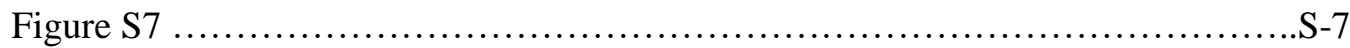

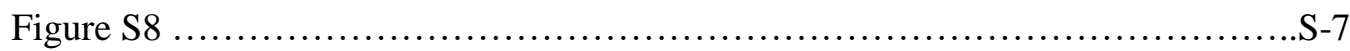

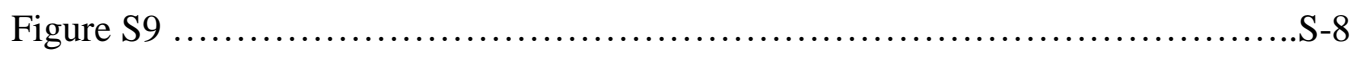

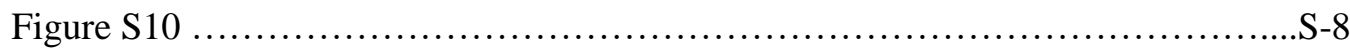

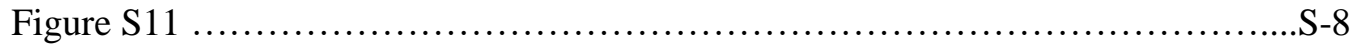

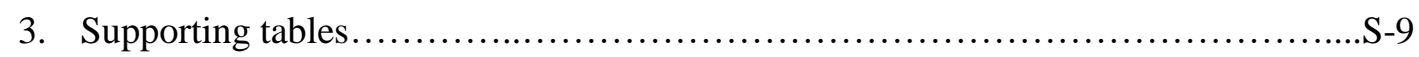

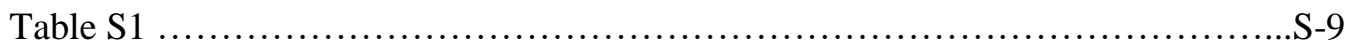

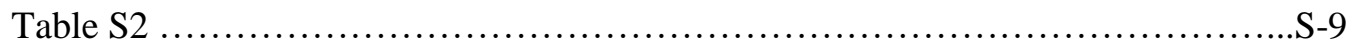

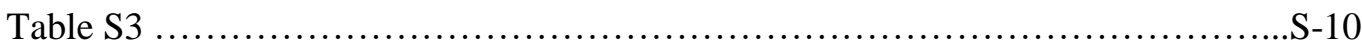

References............................................................ 11 


\section{Experimental details}

\subsection{Materials and Instruments}

All reagents were purchased from Sigma-Aldrich, Acros, Alfa Aesar or TCI, unless specified and used as received. The polymers (PTB7, PTB7-Th, and PBDT-TS1) were purchased from Solarmer Company. PEDOT:PSS (Baytron Clevios P VP AI 4083, Germany) was obtained from Heraeus Group. Ultraviolet photoelectron spectroscopy (UPS) experiments were performed on a Thermo Scientific ESCALab 250Xi spectrometer. The gas discharge lamp was used for UPS, with helium gas admitted and the He I (21.22eV) emission line employed. The helium pressure in the analysis chamber during analysis was about $2 \mathrm{E}-8 \mathrm{mbar}$. The data were acquired with $-10 \mathrm{~V}$ bias. Both one-dimensional (1D) and two-diemensional (2D) GIXRD data were measured on the 1W1A beam line at the Beijing Synchrotron Radiation Facility (BSRF). The 2D images were recorded by a large area MAR345 detector (MAR Research, Hamburg). The 1D GIXRD data, either along the out-of-plane or the in-plane direction, were not line-cut from the corresponding 2D images, but were obtained from the same sample and directly recorded by a silicon drift detector on a 5-circle Huber diffractometer. The authors gratefully acknowledge the assistance of the scientists at the $1 \mathrm{~W} 1 \mathrm{~A}$ station during the experiments. TEM measurements were performed on a JEM-2100F transmission electron microscope operated at $200 \mathrm{kV}$. Absorption spectra were measured on a Hitachi U-3010 UV-vis spectrophotometer. All of the spectroscopic measurements were carried out at room temperature. The thickness of the solid films was measured using a Dektak Profilometer.

\subsection{Sample preparations and characterizations}

Film samples for measurements of absorption, TEM, and UPS were all prepared atop the precoated ITO/PEDOT:PSS substrate via the spin-coating method. The pure donor film was spun-cast from an $o$-DCB solution of $20 \mathrm{mg} / \mathrm{ml}$ and the pure acceptor film was spin-coated from a chloroform solution of $10 \mathrm{mg} / \mathrm{ml}$. All the blend films were fabricated under the optimal conditions. For UV-vis absorption, an ITO/PEDOT:PSS substrate was used as the reference. For TEM, the films were obtained by transferring the floated blend films from the water onto the $\mathrm{Cu}$ grid. For GIXRD, the blend films were prepared on the silicon/PEDOT:PSS substrate.

\subsection{Estimation of HOMO and LUMO energy levels from UPS measurements}

The HOMO levels were determined using ultraviolet photoelectron spectroscopy (UPS) with the incident photon energy, $h v=21.22 \mathrm{eV}$. The HOMO energy is calculated with the equation $E_{\mathrm{HOMO}}=E_{\text {cutoff }}-E_{\text {onset }}-h v, E_{\text {cutoff, }}$, and the $E_{\text {onset }}$ are got from the UPS data. ${ }^{1}$ For example, for 
PTB7, fom Figure S1a, $E_{\text {cutoff }}=16.59 \mathrm{eV}, E_{\text {onset }}=0.39 \mathrm{eV}$. The HOMO energy is obtained with $E_{\mathrm{HOMO}}=16.59-0.39-21.22=-5.02 \mathrm{eV}$. The LUMO energy was calculated using the HOMO level and the optical gap $\left(E_{\mathrm{g}}\right)$ obtained from the onset of absorption shown in Figure 1b. $E_{\mathrm{g}}=1.63 \mathrm{eV}$ for PTB7. Thus, $E_{\mathrm{LUMO}}=1.63-5.02=-3.39 \mathrm{eV}$ for PTB7.

\subsection{Measurements of the hole and electron mobility by the space-charge limited current (SCLC) method}

The hole-only devices were fabricated with configuration of ITO/PEDOT:PSS/blend (200$250 \mathrm{~nm}$ )/Au (or ITO/PEDOT:PSS/MeOH/blend/Au). The electron-only devices were fabricated with a configuration of ITO/titanium (diisopropoxide) bis(2,4-pentanedionate) $($ TIPD, $20 \mathrm{~nm}) / \quad$ blend $\quad(150 \mathrm{~nm}) / \mathrm{Al} \quad(100 \mathrm{~nm}) \quad$ (or $\quad$ ITO/TIPD/blend/Ca/Al, ITO/TIPD/blend/PDINO/Al). Since the HOMO and LUMO energy levels of TIPD are of $3.91 \mathrm{eV}$ and $-6.0 \mathrm{eV}$, respectively, it can be used to fabricate the electron-only SCLC device. The TIPD buffer layer was prepared by spin-coating a $3.5 \mathrm{wt} \%$ TIPD isopropanol solution onto the pre-cleaned ITO substrate and then baked at $150{ }^{\circ} \mathrm{C}$ for $10 \mathrm{~min}$ to convert TIPD into TOPD. ${ }^{2}$ Subsequently, the blend was spin-coated on it under the same condition as preparation of the optimal solar cell. The Au or Al layer was thermally deposited on the top of the blend in vacuum. The Au layer was deposited under a low speed ( $1 \AA / 10 \mathrm{~s})$ to avoid the penetration of $\mathrm{Au}$ atoms into the active layer. The Al layer was deposited at a speed of $1 \AA / \mathrm{s}$. The hole and electron mobility was extracted by fitting the current density-voltage curves using the Mott-Gurney law, ${ }^{3,4}$ Equation (1)

$J_{\mathrm{SCL}}=9 \varepsilon \varepsilon_{0} \mu V^{2} /\left(8 L^{3}\right)$

where $\varepsilon$ is the dielectric constant of the polymer, $\varepsilon_{0}$ is the permittivity of the vacuum

$\left(8.85419 \times 10^{-12} \mathrm{CV}^{-1} \mathrm{~m}^{-1}\right), \mu$ is the zero-field mobility, $J$ is the current density, $L$ is the thickness of the active layer, and $V=V_{\text {appl }}-V_{\mathrm{bi}}$, here $V_{\text {appl }}$ is the applied potential, and $V_{\mathrm{bi}}$ the built-in potential which results from the difference in the work function of the anode and the cathode (in the hole-only device, $V_{\mathrm{bi}}=0.1 \mathrm{~V}$, and in the electron-only device, $V_{b i}=0.4 \mathrm{~V}$ ). The hole and electron mobility of the solar cell blend are deduced from the intercept value of $9 \varepsilon \varepsilon_{0} \mu /\left(8 L^{3}\right)$ by linearly plotting $\ln (J) v s . \ln (V)$ (the slope of $\ln (J)$ vs. $\ln (V)$ is $\approx 2$ ).

\subsection{Incident light-power dependent measurements of $J-V$ characteristics}

The light from a AAA-grade AM 1.5G light source was allowed to pass a series of neutral density filters (metallic UV-VIS-NIR, Andover) and the incident light power was controlled from $100 \mathrm{~mW} / \mathrm{cm}^{2}$ to $1 \mathrm{~mW} / \mathrm{cm}^{2}$. 


\section{Supporting figures}

Figure S1. UPS spectra of the onset (inset) and the secondary edge region of PTB7 (a), PTB7-Th (b), PBDT-TS1 (c), and PDI (d).

(a)

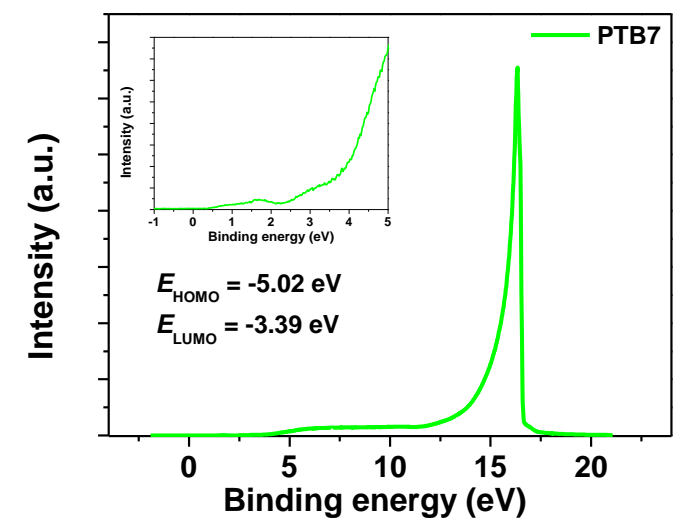

(c)

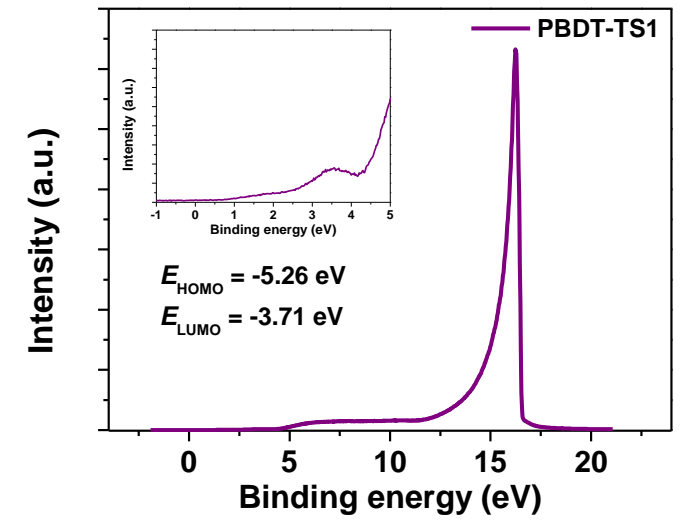

(b)

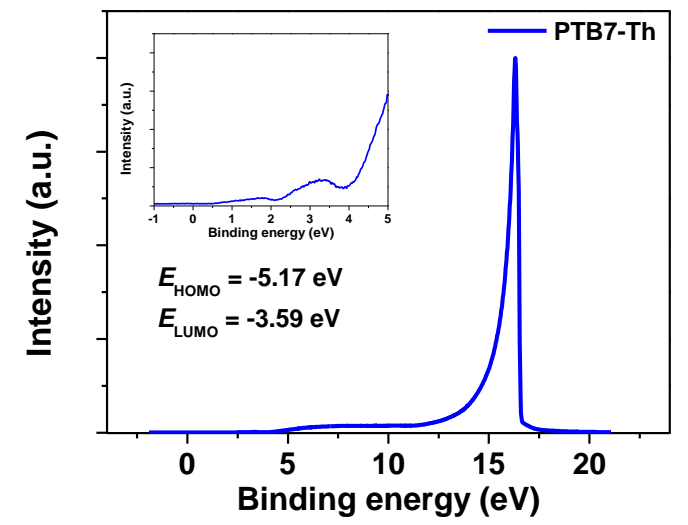

(d)

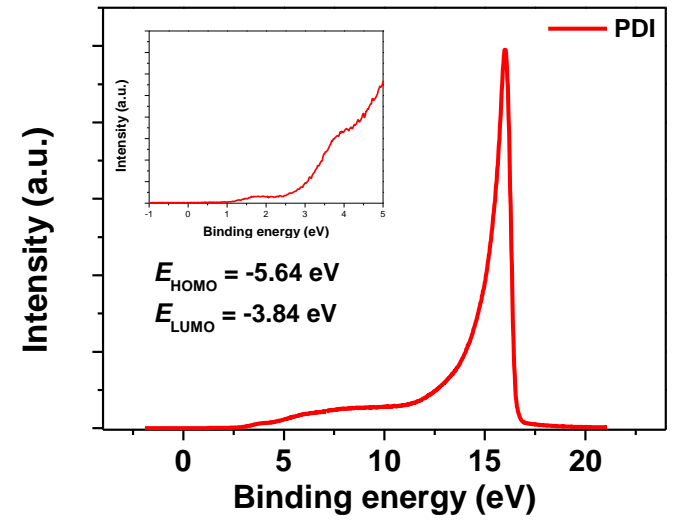

Figure S2. Plots of $J-V$ obtained from the PTB7-Th:PDI based electron-only (a) and holeonly (b) device, which were estimated using the SCLC method. The devices were fabricated under the optimal conditions of B, B+C, and C. Green lines represent fits of the curves using the Mott-Gurney relationship.

(a)

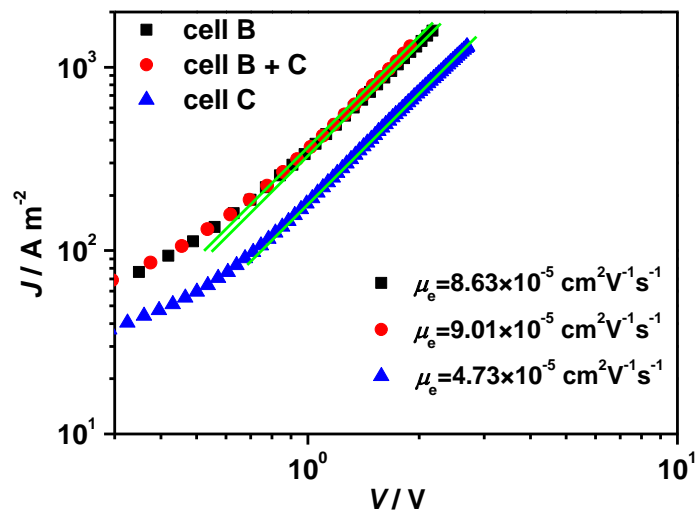

(b)

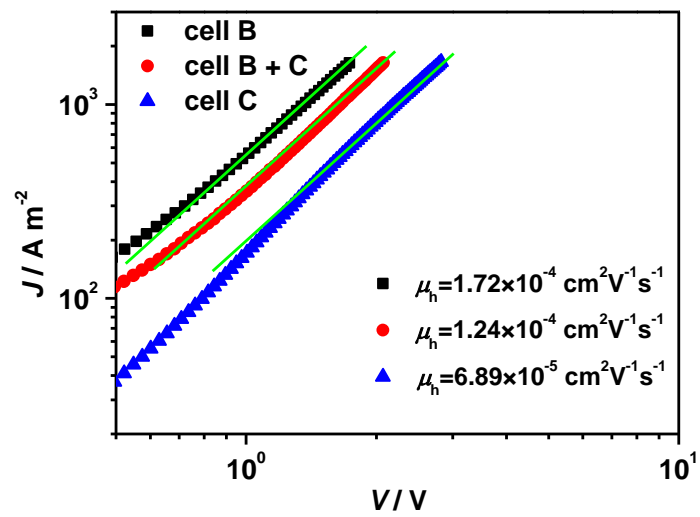


Figure S3. TEM images of the solar cell blends obtained under conditions B (a), B+C (b) and C (c), respectively, based on PTB7-Th.
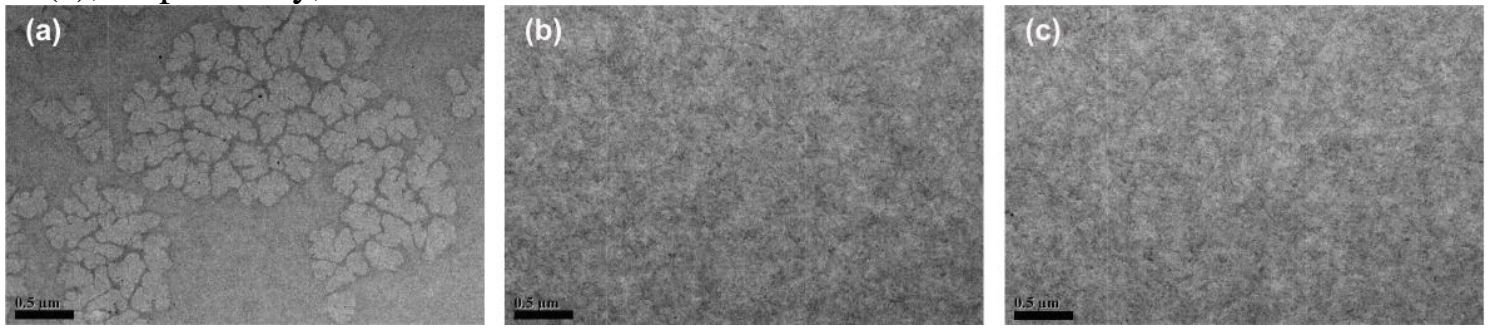

Figure S4. Two-dimensional (2D) grazing-incidence X-ray diffraction (GIXRD) images of the pure PEDOT:PSS film (a) and the PTB7-Th:PDI based solar cell blend films, which were fabricated under the optimal conditions of B (b), B+C (c), and C (d).
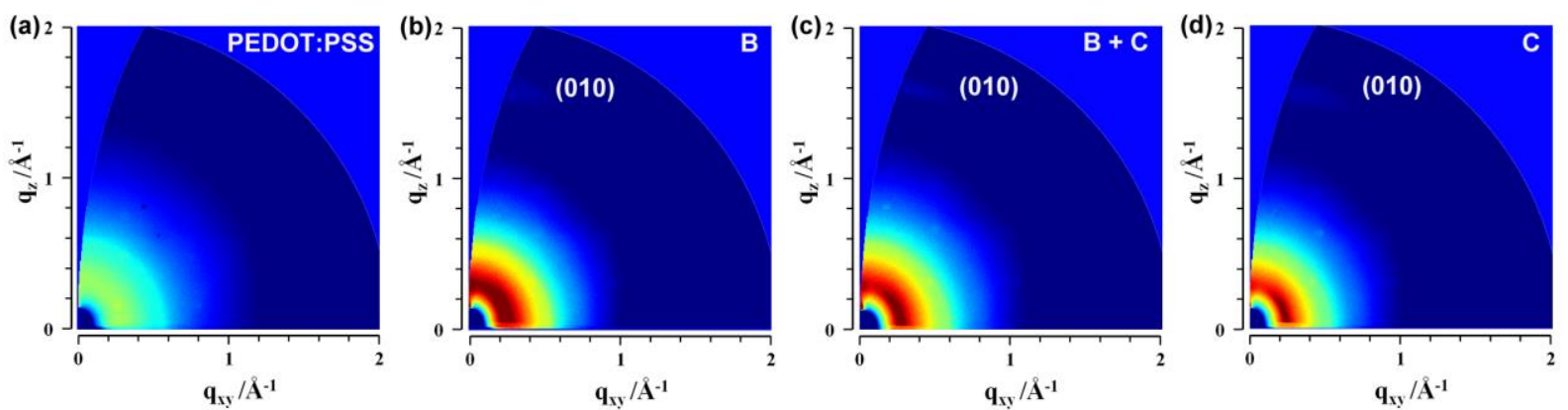

Figure S5. Light-intensity dependence of (a) $J_{\mathrm{sc}}$ and (b) $V_{\text {oc }}$ obtained from the PTB7-Th:PDI based optimal cells under conditions of $\mathrm{B}, \mathrm{B}+\mathrm{C}$, and $\mathrm{C}$.

(a)

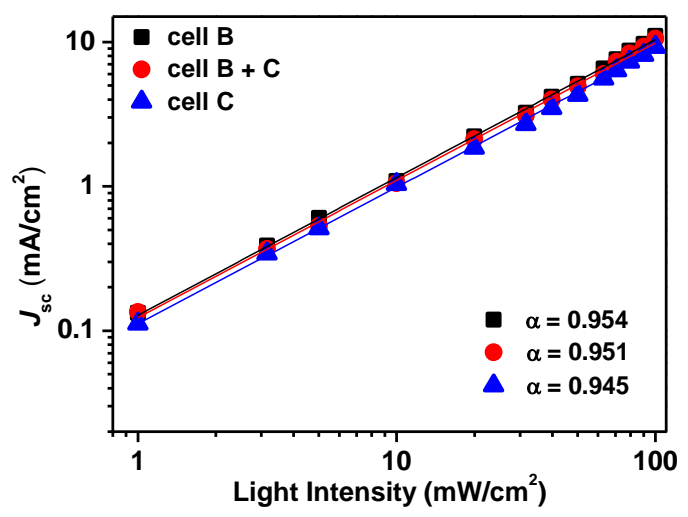

(b)

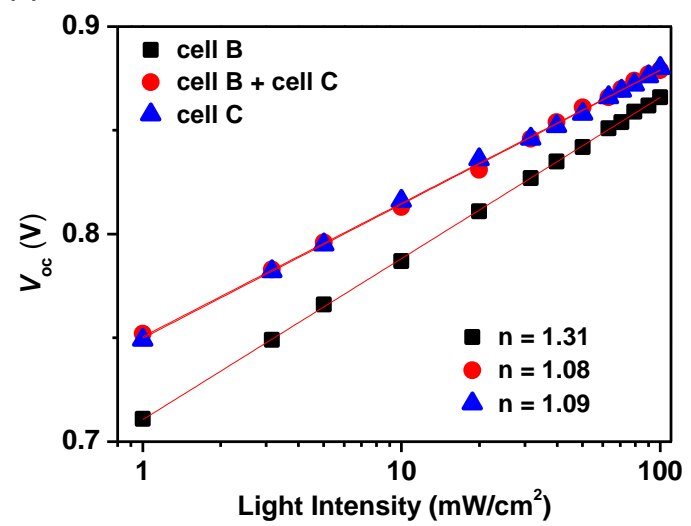


Figure S6. Two-dimensional (2D) grazing-incidence X-ray diffraction (GIXRD) images of the pure (a-c) and blend films (d-f) based PTB7 (a, d), PTB7-Th (b, e), and PBDT-TS1(c, f).
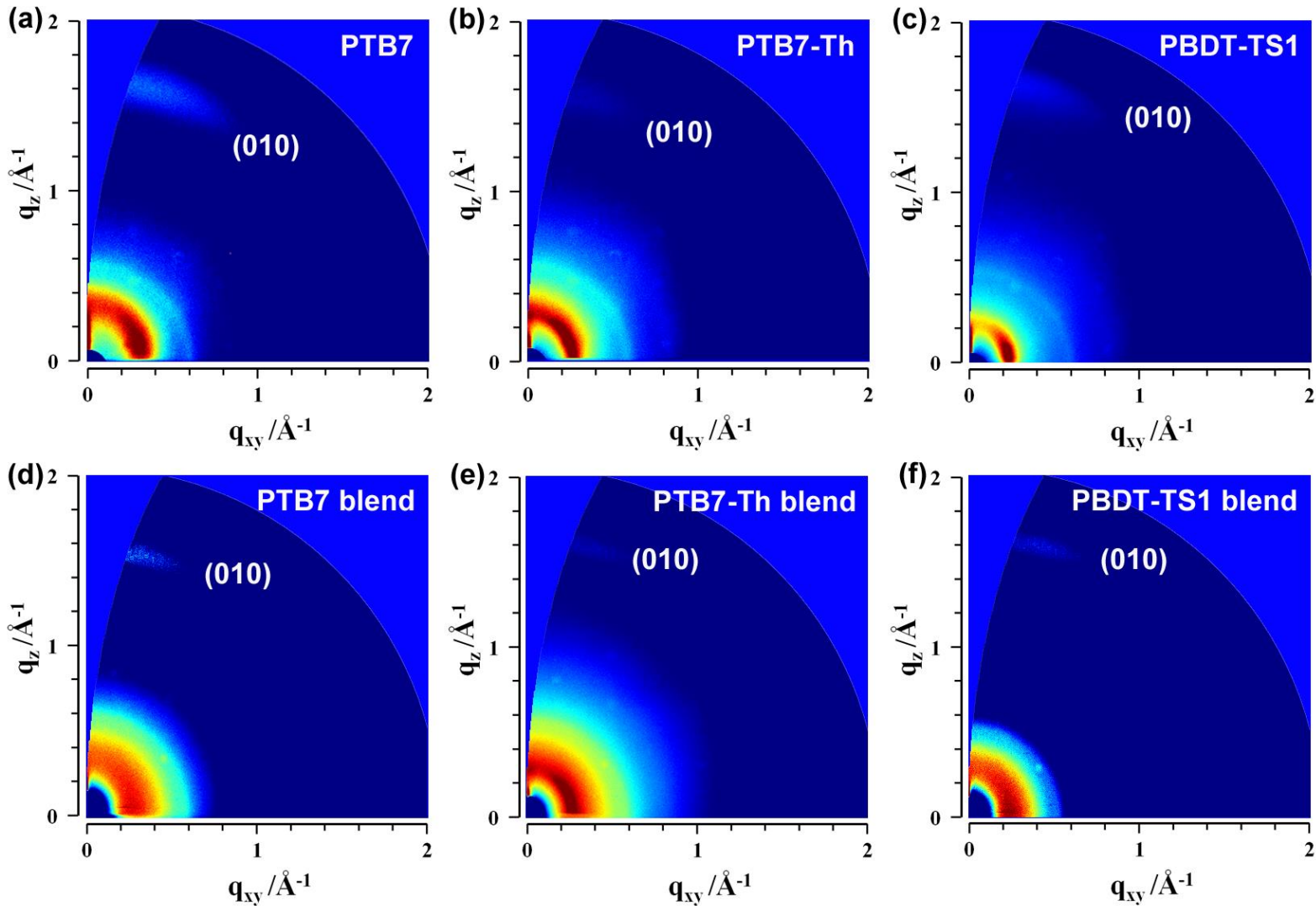

Figure S7. TEM images of the solar cell blends based on PTB7 (a), PTB7-Th (b), and PBDTTS1 (c).
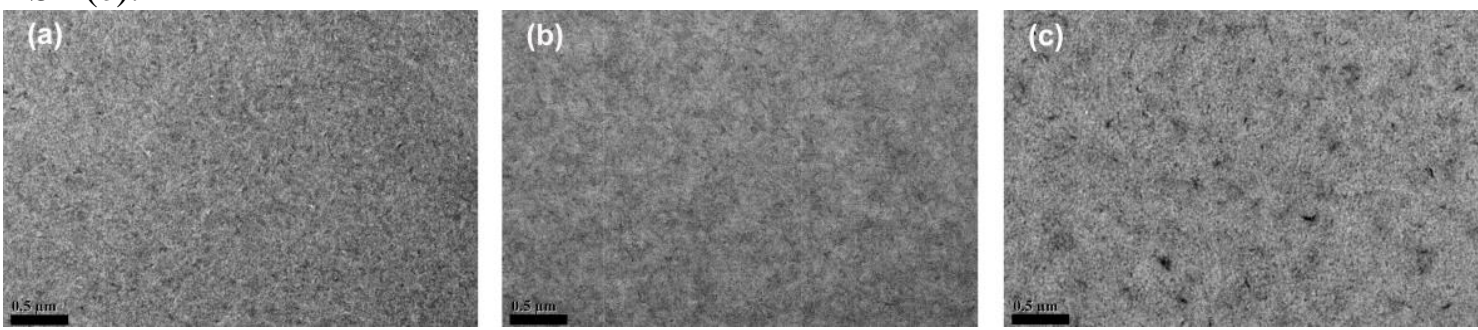

Figure S8. Light-intensity dependence of (a) $J_{\text {sc }}$ and (b) $V_{\text {oc }}$ obtained from the optimal cells based on PTB7, PTB7-Th, and PBDT-TS1.

(a)

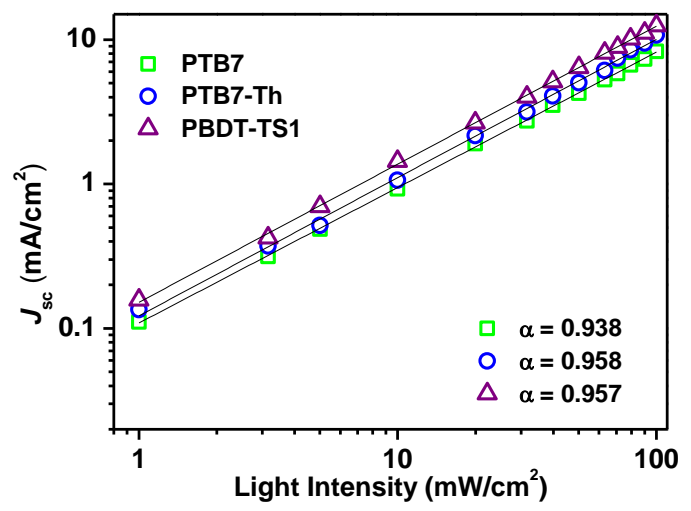

(b)

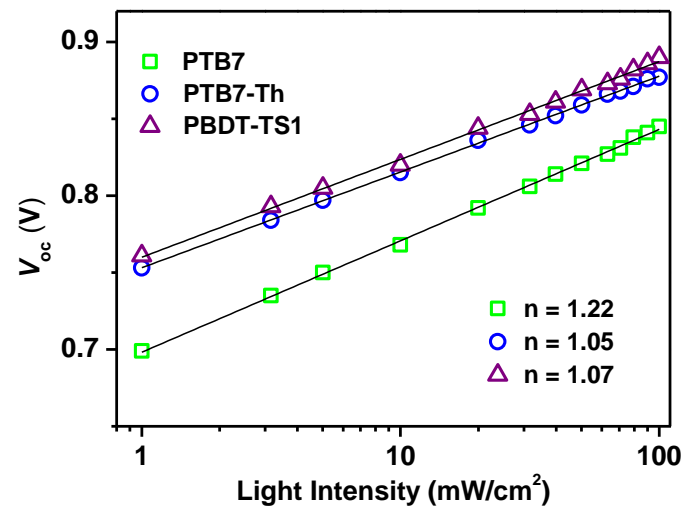


Figure S9. Plots of $J-V$ obtained from the electron-only (a) and hole-only (b) device (PTB7, PTB7-Th, and PBDT-TS1), which were estimated using the SCLC method. Black lines represent fits of the curves using the Mott-Gurney relationship.

(a)

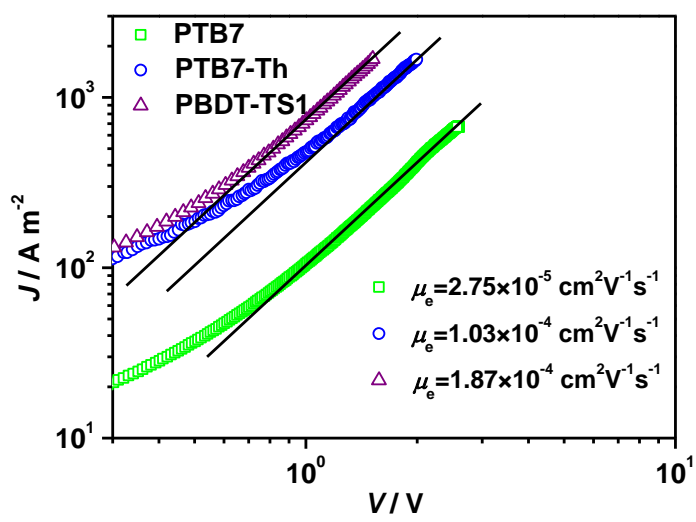

(b)

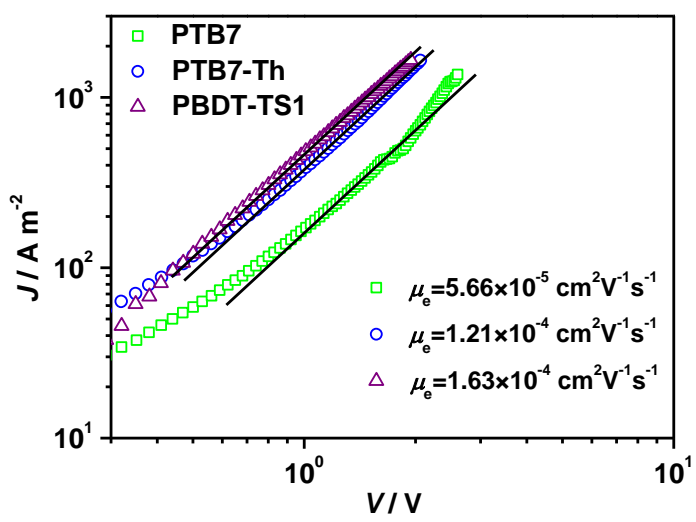

Figure S10. EQE spectra of the best cells under three device constructions.

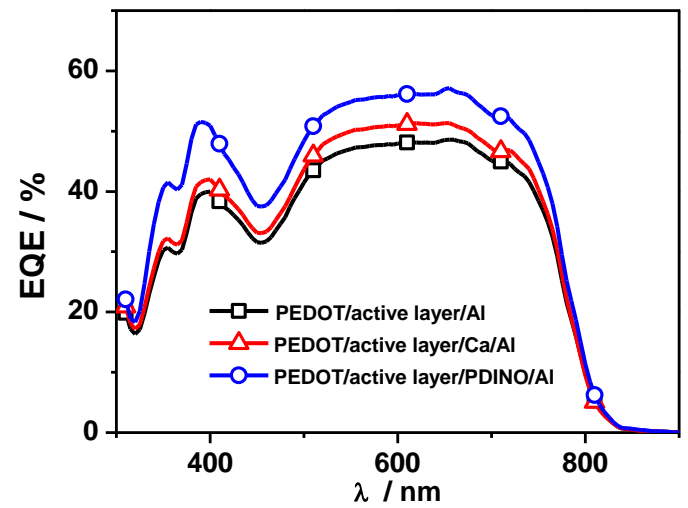

Figure S11. Plots of $J-V$ obtained from three electron-only device constructions (PBDT-TS1) with different cathode interlayers, which were estimated using the SCLC method. Green lines represent fits of the curves using the Mott-Gurney relationship.

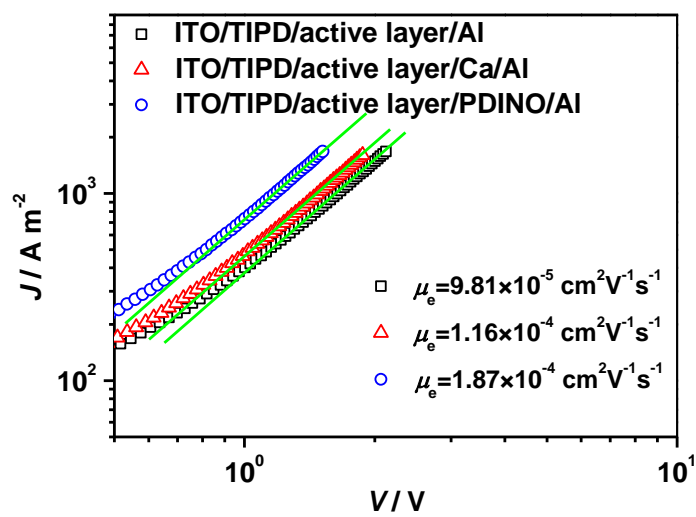




\section{Supporting tables}

Table S1. The photovoltaic properties of the PTB7-Th:PDI based solar cells obtained by screening the [DIO] and D/A weight ratio, while the time for SVA (condition C) is $30 \mathrm{~min}^{a}$

\begin{tabular}{ccccccc}
\hline Polymer & D/A & [DIO] $[\%]$ & $V_{\mathrm{oc}}[\mathrm{V}]^{b}$ & $J_{\mathrm{sc}}[\mathrm{mA} \mathrm{cm}]^{b}$ & $F F^{b}$ & ${\text { PCE }[\%]^{b}}^{-2}$ \\
\hline PTB7-Th & $1: 1$ & 1 & $0.874 \pm 0.005$ & $6.46 \pm 0.25$ & $0.546 \pm 0.010$ & $3.07 \pm 0.23(3.31)$ \\
& $1: 1$ & 3 & $0.875 \pm 0.008$ & $8.36 \pm 0.10$ & $0.535 \pm 0.014$ & $3.91 \pm 0.17(4.09)$ \\
& $1: 1$ & 5 & $0.877 \pm 0.006$ & $7.62 \pm 0.23$ & $0.525 \pm 0.013$ & $3.49 \pm 0.26(3.77)$ \\
& $2: 1$ & 3 & $0.868 \pm 0.005$ & $3.86 \pm 0.33$ & $0.493 \pm 0.016$ & $1.64 \pm 0.21(1.86)$ \\
& $1.5: 1$ & 3 & $0.873 \pm 0.006$ & $6.25 \pm 0.21$ & $0.498 \pm 0.009$ & $2.71 \pm 0.16(2.89)$ \\
& $1: 1.5$ & 3 & $0.877 \pm 0.009$ & $9.56 \pm 0.25$ & $0.539 \pm 0.013$ & $4.51 \pm 0.25(4.77)$ \\
& $1: 2$ & 3 & $0.877 \pm 0.010$ & $8.92 \pm 0.26$ & $0.543 \pm 0.015$ & $4.24 \pm 0.20(4.46)$
\end{tabular}

Table S2. The photovoltaic properties of the PTB7-Th:PDI based solar cells obtained by screening the time for SV or SVA, while other parameters of [DIO] and D/A weight ratio were maintained as $3 \%$ and $1: 1.5$, respectively. ${ }^{a}$

\begin{tabular}{|c|c|c|c|c|c|c|}
\hline Polymer & Condition & Time [min] & $V_{\mathrm{oc}}[\mathrm{V}]^{b}$ & $J_{\mathrm{sc}}[\mathrm{mA} \mathrm{cm}]^{-2}$ & $F F^{b}$ & $\operatorname{PCE}[\%]^{b}$ \\
\hline \multirow[t]{15}{*}{ PTB7-Th } & A & 120 & $0.884 \pm 0.008$ & $9.17 \pm 0.21$ & $0.430 \pm 0.016$ & $3.47 \pm 0.24$ \\
\hline & $\mathrm{B}$ & $15+0$ & $0.874 \pm 0.007$ & $10.82 \pm 0.22$ & $0.431 \pm 0.015$ & $4.07 \pm 0.29(4.36)$ \\
\hline & B & $30+0$ & $0.874 \pm 0.006$ & $10.89 \pm 0.19$ & $0.453 \pm 0.013$ & $4.30 \pm 0.25(4.59)$ \\
\hline & B & $45+0$ & $0.870 \pm 0.008$ & $11.29 \pm 0.13$ & $0.458 \pm 0.017$ & $4.46 \pm 0.16(4.64)$ \\
\hline & B & $60+0$ & $0.869 \pm 0.006$ & $11.27 \pm 0.16$ & $0.461 \pm 0.015$ & $4.49 \pm 0.13$ \\
\hline & B & $120+0$ & $0.870 \pm 0.007$ & $11.26 \pm 0.17$ & $0.459 \pm 0.021$ & $4.46 \pm 0.17(4.64)$ \\
\hline & $\mathrm{B}+\mathrm{C}$ & $30+15$ & $0.876 \pm 0.009$ & $10.89 \pm 0.22$ & $0.523 \pm 0.013$ & $4.96 \pm 0.24(5.23)$ \\
\hline & $\mathrm{B}+\mathrm{C}$ & $30+20$ & $0.878 \pm 0.010$ & $10.14 \pm 0.17$ & $0.539 \pm 0.017$ & $4.79 \pm 0.23(5.04)$ \\
\hline & $\mathrm{C}$ & $0+5$ & $0.878 \pm 0.005$ & $10.17 \pm 0.28$ & $0.485 \pm 0.010$ & $4.31 \pm 0.20(4.53)$ \\
\hline & $\mathrm{C}$ & $0+10$ & $0.875 \pm 0.007$ & $10.11 \pm 0.15$ & $0.507 \pm 0.018$ & $4.46 \pm 0.25(4.74)$ \\
\hline & $\mathrm{C}$ & $0+15$ & $0.872 \pm 0.009$ & $10.03 \pm 0.15$ & $0.528 \pm 0.014$ & $4.60 \pm 0.29(4.92)$ \\
\hline & $\mathrm{C}$ & $0+20$ & $0.878 \pm 0.005$ & $9.98 \pm 0.17$ & $0.538 \pm 0.015$ & $4.70 \pm 0.18(4.89)$ \\
\hline & $\mathrm{C}$ & $0+30$ & $0.877 \pm 0.009$ & $9.56 \pm 0.25$ & $0.539 \pm 0.013$ & $4.51 \pm 0.25(4.77)$ \\
\hline & $\mathrm{C}$ & $0+45$ & $0.877 \pm 0.006$ & $9.12 \pm 0.23$ & $0.549 \pm 0.011$ & $4.37 \pm 0.27(4.66)$ \\
\hline & $\mathrm{C}$ & $0+60$ & $0.876 \pm 0.008$ & $8.98 \pm 0.17$ & $0.553 \pm 0.012$ & $4.34 \pm 0.16(4.50)$ \\
\hline
\end{tabular}

${ }^{a} \mathrm{Ca} / \mathrm{Al}$ was employed as the cathode. ${ }^{b}$ Average values from 10 devices. 
Table S3. Summary of photovoltaic properties of the PTB7, PTB7-Th and PBDT-TS1 based solar cells with $\mathrm{PDINO} / \mathrm{Al}$ as the cathode.

\begin{tabular}{|c|c|c|c|c|c|c|c|c|}
\hline Polymer & $\mathrm{D} / \mathrm{A}$ & $\begin{array}{c}\text { DIO }] \\
{[\%]} \\
\end{array}$ & Condition & Time [min] & $V_{\mathrm{oc}}[\mathrm{V}]^{a}$ & $J_{\mathrm{sc}}\left[\mathrm{mA} \mathrm{cm}^{-2}\right]^{a}$ & $F F^{a}$ & $\operatorname{PCE}[\%]^{a}$ \\
\hline PTB7-Th & $1: 1.5$ & 3 & $\mathrm{~B}+\mathrm{C}$ & $30+15$ & $\begin{array}{c}0.876 \pm \\
0.007\end{array}$ & $11.14 \pm 0.21$ & $\begin{array}{c}0.583 \pm \\
0.012\end{array}$ & $5.65 \pm 0.20(5.87)$ \\
\hline \multirow[t]{6}{*}{ PTB7 } & $1: 1$ & 3 & A & 60 & $\begin{array}{c}0.841 \pm \\
0.005\end{array}$ & $6.89 \pm 0.15$ & $\begin{array}{c}0.358 \pm \\
0.021\end{array}$ & $2.06 \pm 0.16(2.24)$ \\
\hline & $1: 1$ & 3 & $\mathrm{C}$ & $0+60$ & $\begin{array}{c}0.840 \pm \\
0.005\end{array}$ & $7.74 \pm 0.20$ & $\begin{array}{c}0.527 \pm \\
0.018\end{array}$ & $3.39 \pm 0.15(3.58)$ \\
\hline & $1: 1.5$ & 3 & A & 60 & $\begin{array}{c}0.841 \pm \\
0.006\end{array}$ & $7.51 \pm 0.25$ & $\begin{array}{c}0.375 \pm \\
0.014\end{array}$ & $2.33 \pm 0.17(2.54)$ \\
\hline & $1: 1.5$ & 3 & $\mathrm{C}$ & $0+60$ & $\begin{array}{c}0.840 \pm \\
0.006\end{array}$ & $8.46 \pm 0.19$ & $\begin{array}{c}0.552 \pm \\
0.017\end{array}$ & $3.88 \pm 0.21(4.10)$ \\
\hline & $1: 2$ & 3 & A & 60 & $\begin{array}{c}0.845 \pm \\
0.008\end{array}$ & $6.01 \pm 0.16$ & $\begin{array}{c}0.396 \pm \\
0.021\end{array}$ & $1.97 \pm 0.22(2.21)$ \\
\hline & $1: 2$ & 3 & $\mathrm{C}$ & $0+60$ & $\begin{array}{c}0.846 \pm \\
0.006\end{array}$ & $6.45 \pm 0.18$ & $\begin{array}{c}0.586 \pm \\
0.014\end{array}$ & $3.17 \pm 0.21(3.41)$ \\
\hline \multirow[t]{5}{*}{ PBDT-TS1 } & $1: 1.5$ & 3 & A & $120+0$ & $\begin{array}{c}0.903 \pm \\
0.009\end{array}$ & $8.10 \pm 0.27$ & $\begin{array}{c}0.482 \pm \\
0.016\end{array}$ & $3.50 \pm 0.28(3.79)$ \\
\hline & $1: 1.5$ & 3 & B & $30+0$ & $\begin{array}{c}0.887 \pm \\
0.005\end{array}$ & $13.23 \pm 0.19$ & $\begin{array}{c}0.594 \pm \\
0.019\end{array}$ & $6.94 \pm 0.27(7.24)$ \\
\hline & $1: 1.5$ & 3 & B & $60+0$ & $\begin{array}{c}0.886 \pm \\
0.007\end{array}$ & $12.97 \pm 0.28$ & $\begin{array}{c}0.582 \pm \\
0.019\end{array}$ & $6.66 \pm 0.37(7.06)$ \\
\hline & $1: 1.5$ & 3 & $\mathrm{C}$ & $0+15$ & $\begin{array}{c}0.890 \pm \\
0.006\end{array}$ & $12.39 \pm 0.16$ & $\begin{array}{c}0.553 \pm \\
0.026\end{array}$ & $6.07 \pm 0.35(6.48)$ \\
\hline & $1: 1.5$ & 3 & $\mathrm{C}$ & $0+30$ & $\begin{array}{c}0.889 \pm \\
0.006\end{array}$ & $12.06 \pm 0.19$ & $\begin{array}{c}0.574 \pm \\
0.020\end{array}$ & $6.06 \pm 0.28(6.37)$ \\
\hline
\end{tabular}




\section{References}

(1) Gong, X.; Tong, M.; Brunetti, F. G.; Seo, J.; Sun, Y.; Moses, D.; Wudl, F.; Heeger, A. J. Bulk Heterojunction Solar Cells with Large Open-Circuit Voltage: Electron Transfer with Small Donor-Acceptor Energy Offset. Adv. Mater. 2011, 23, 2272-2277.

(2) Tan, Z; Zhang, W; Zhang, Z; Qian, D.; Huang, Y.; Hou, J.; Li, Y. High-Performance Inverted Polymer Solar Cells with Solution-Processed Titanium Chelate as Electron-Collecting Layer on ITO Electrode. Adv. Mater. 2012, 24, 1476-1481.

(3) Malliaras, G. G.; Salem, J. R.; Brock, P. J.; Scott, C. Electrical Characteristics and Efficiency of SingleLayer Organic Light-Emitting Diodes. Phys. Rev. B 1998, 58, R13411-R13414.

(4) Chu, T.-Y.; Song, O.-K. Hole Mobility of $N, N^{\prime}$-bis(naphthalen-1-yl)- $N, N^{\prime}$-bis(phenyl) benzidine Investigated by Using Space-Charge-Limited Currents. Appl. Phys. Lett. 2007, 90, 203512. 